\title{
Aplicação do método UEP na determinação dos custos de uma empresa de revestimentos cerâmicos
}

Leopoldo Pedro Guimarães Filho
Mestrado em Engenharia de Produção pela Universidade Federal de Santa Catarina -

UFSC

Coordenador do Curso de Engenharia de Produção da Universidade do Extremo Sul

Catarinense - UNESC

Av. Universitária, 1105. Universitário. Criciúma/SC. CEP: 88806-000

E-mail: Ipg@unesc.net

Vilson Menegon Bristot

Doutorado em Engenharia de Minas, Metalúrgica e de Materiais pela Universidade

Federal do Rio Grande do Sul - UFRGS

Professor da Universidade do Extremo Sul Catarinense - UNESC Av. Universitária, 1105. Universitário. Criciúma/SC. CEP: 88806-000

E-mail: vilson.bristot@unesc.net

Lucas Da Rold Marques

Graduação em Engenharia de Produção pela Universidade do Extremo Sul Catarinense - UNESC

Av. Universitária, 1105. Universitário. Criciúma/SC. CEP: 88806-000

E-mail: lucas.roldmarques@gmail.com

Norton Ferreira Feil

Doutorado em Engenharia de Minas, Metalúrgica e de Materiais pela Universidade

Federal do Rio Grande do Sul - UFRGS

Professor da Universidade do Extremo Sul Catarinense - UNESC Av. Universitária, 1105. Universitário. Criciúma/SC. CEP: 88806-000

E-mail:nff@unesc.net

Tiago Comin Colombo Mestrado em andamento em Desenvolvimento Socioeconômico pela Universidade do Extremo Sul Catarinense - UNESC Av. Universitária, 1105. Universitário. Criciúma/SC. CEP: 88806-000 E-mail: tiagocolombo@gmail.com

\section{RESUMO}

Em um mercado cada vez mais competitivo, as empresas buscam novas ferramentas gerenciais que proporcionem o aperfeiçoamento das atividades e produtos prestados. Neste cenário, a contabilidade de custos passa a se tornar um importante instrumento de controle e de suporte às tomadas de decisões empresariais. No presente trabalho, foi estudado o Setor de Revestimentos Cerâmicos, tendo como objetivo realizar a 
Aplicação do método UEP na determinação dos custos de uma empresa de revestimentos cerâmicos

Leopoldo Pedro Guimarães Filho, BristotMenegon Vilson, Lucas Da Rold Marques, Norton Ferreira Feil,

Tiago Comin Colombo

aplicação do método da unidade de esforço de produção (UEP) na determinação dos custos de produção. Este método se aplica apenas para os custos de transformação, ou seja, os custos relacionados à mão de obra direta e aos custos indiretos de fabricação. O desenvolvimento deste trabalho foi baseado nas informações geradas pelo método de custeio utilizado pela empresa, o método do centro de custos. Analisando as informações dos custos da empresa estudada, pode ser observado que $51 \%$ classificam-se como custos indiretos, que não possuem relação direta com um produto. Pode-se verificar, com este estudo, a comprovação da viabilidade de aplicação deste método de custeio em uma indústria cerâmica, obtendo-se, através do mesmo, maior precisão por meio de critérios de rateio mais consistentes para apropriação dos custos aos produtos, simplicidade de operacionalização para a determinação dos custos, além de avaliar o desempenho da capacidade produtiva da empresa.

Palavras-chave: Custos de produção. Custos indiretos. Indústria cerâmica. Unidade de Esforço de Produção - UEP. Capacidade produtiva.

\section{Application of the UEP method for the determination of the costs of a ceramic coating company}

\section{ABSTRACT}

In an increasingly competitive market, companies are looking for new management tools that could provide the improvement of the activities and products provided. In this scenario, the cost accounting goes on to become an important tool to control and support the acquisition of business decisions. In the present work, the Ceramic Coatings Sector was studied, with the objective to carry out the application of the method of the Production Effort Unit (PEU) in the determination of production costs. This method is applied only to the processing costs, in other words costs related to direct labor and indirect manufacturing costs. The development of this work was based on information generated by the costing method used by the company, i.e. the method of cost center. Analyzing the information of the company studied, it can be observed that $51 \%$ of the costs are classified as indirect costs, which have no direct relation with a product. With this study, we can verify the feasibility of applying this costing method in a ceramic industry, obtaining, through the same, greater accuracy through more consistent assessment criteria for appropriation of costs to products, operational simplicity for determining costs, and to evaluate the performance of the productive capacity of the company.

Keywords: Production costs. Indirect costs. Ceramics industry. Unit of Effort of Production - UEP. Productive capacity. 
Aplicação do método UEP na determinação dos custos de uma empresa de revestimentos cerâmicos Leopoldo Pedro Guimarães Filho, BristotMenegon Vilson, Lucas Da Rold Marques, Norton Ferreira Feil, Tiago Comin Colombo

\section{INTRODUÇÃO}

Nas empresas de manufatura, informações relacionadas à produção e à identificação dos custos de produção são necessárias para análise e gerenciamento de um negócio. Considerando o cenário de competitividade do mercado atual e o momento de instabilidade financeira do país, as empresas necessitam obter cada vez mais dados confiáveis para tratar seus custos de forma correta diante de uma tomada de decisão.

Neste contexto, cresce a necessidade informacional nas empresas, pois as informações empresariais são utilizadas pela gestão estratégica para identificar novas oportunidades. Vale salientar que o custo de produto ou de processo se torna o principal aspecto a ser considerado na avaliação das alternativas estratégicas.Bornia (2010) afirma que as informações fornecidas pela contabilidade de custos são potencialmente úteis ao auxílio gerencial, extrapolando a mera determinação contábil do resultado do período. Os sistemas de custos podem contribuir com o auxílio ao controle e à tomada de decisões.

Desse modo, para fazer a gestão estratégica eficaz e, por consequência, melhorar resultados, torna-se necessário o emprego de uma metodologia de custeio adequada às necessidades da empresa. Dentre as metodologias de custeio existentes, o método de Unidade de Esforço de Produção (UEP) surgiu como alternativa de melhoria para o rateio dos custos indiretos de fabricação no ambiente de manufatura.

Segundo Allora e (2010), o método UEP é utilizado por empresas de diversos segmentos, principalmente na região Sul do Brasil e em Santa Catarina, pelo fato de seu idealizador, Prof. Franz Allora, ter sido morador dessa região do país. O método da UEP, além de ter a finalidade voltada à contabilidade dos custos, pode ser considerado ferramenta de gerenciamento e planejamento de produção, que tem por objetivo a maximização da produção e a diminuição do custo do produto.

No decorrer da pesquisa bibliográfica, pode ser verificado que não há muitos estudos voltados à aplicação do método UEP no processo cerâmico, constatando-se 
Aplicação do método UEP na determinação dos custos de uma empresa de revestimentos cerâmicos

Leopoldo Pedro Guimarães Filho, BristotMenegon Vilson, Lucas Da Rold Marques, Norton Ferreira Feil, Tiago Comin Colombo

que as indústrias cerâmicas ainda preferem adotar os sistemas tradicionais, o que acabou gerando maior relevância deste trabalho.

O objetivo deste estudo foi realizar a aplicação do método da unidade de esforço de produção (UEP), simulando a implantação em uma linha de produção de uma empresa de revestimentos cerâmicos localizada no sul de Santa Catarina.

\section{REFERENCIAL TEÓRICO}

\subsection{Indústria de Revestimentos Cerâmicos}

Segundo a Anfacer (2016), a cerâmica é praticamente tão antiga quanto a descoberta do fogo. Nos últimos anos, acompanhando a evolução industrial, a indústria cerâmica adotou a produção em massa, garantida pela indústria de equipamentos e a introdução de técnicas de gestão, incluindo o controle de matérias primas, dos processos e dos produtos fabricados. Os revestimentos cerâmicos são usados na construção civil para revestimento de paredes, pisos, bancadas e piscinas de ambientes internos e externos. A tecnologia do porcelanato trouxe produtos de qualidade técnica e estética refinada, que, em muitos casos, se assemelham às pedras naturais.

As placas cerâmicas são constituídas, em geral, de três camadas: (a) o suporte ou biscoito; (b) o engobe, que tem função impermeabilizante e garante a aderência da terceira camada; e c) o esmalte, camada vítrea que também impermeabiliza, além de decorar uma das faces da placa (ANFACER, 2016).

Pinto Junior (2008) cita que a produção de revestimentos cerâmicos pode ser classificada de acordo com o processo de preparação da massa: via úmida ou via seca. No processo via úmida, há a mistura de diversas matérias primas que são moídas e homogeneizadas em meio aquoso e, apesar de incorrer em custos energéticos maiores, comparado ao processo via seca, deixa a massa mais homogênea, conferindo ao produto final melhor qualidade. Na via seca, não há a mistura de matérias primas e 
Aplicação do método UEP na determinação dos custos de uma empresa de revestimentos cerâmicos Leopoldo Pedro Guimarães Filho, BristotMenegon Vilson, Lucas Da Rold Marques, Norton Ferreira Feil, Tiago Comin Colombo

homogeneização, como ocorre na via úmida. Entretanto, neste processo se ganha em economia nos custos de manutenção, energético e ambiental.

O setor brasileiro de revestimentos cerâmicos é constituído por 93 empresas, com maior concentração nas regiões Sudeste e Sul do país. O Brasil é considerado o segundo maior produtor de revestimentos cerâmicos do mundo, superado apenas, em termos de volume, pela China. A região de Criciúma, em Santa Catarina, que tem reconhecimento como pólo internacional, concentra as maiores empresas brasileiras. Nessa região, as empresas produzem com tecnologia via úmida e competem por design e marca, em faixas de preços mais altas (ANFACER, 2016).

\subsection{Gerenciamento dos Custos de Produção}

Bertó e Beulke (2013) afirmam que uma empresa, para se manter competitiva em matéria de preços, precisa cada vez mais de uma gestão eficiente de seus custos. Bornia (2010) cita que as informações fornecidas pela contabilidade de custos são potencialmente úteis ao auxílio gerencial, extrapolando a mera determinação contábil do resultado do período. Os sistemas de custos podem contribuir com o auxílio ao controle e à tomada de decisões.

Segundo Wernke (2004), a superioridade competitiva de uma empresa está relacionada com a habilidade em estruturar sua cadeia de valores, estabelecer um posicionamento estratégico condizente com a realidade de seus negócios e gerenciar de forma eficaz os fatores que direcionam os custos.

Vale ressaltar que uma avaliação inadequada das informações de custos poderá induzir os gestores a tomarem decisões que não trarão os resultados desejados. Para melhorar a tomada de decisão dos processos de fabricação, Bornia propõe a separação dos sistemas de custos em métodos e princípios de custeio, conforme se apresenta na Figura 1. 
Aplicação do método UEP na determinação dos custos de uma empresa de revestimentos cerâmicos Leopoldo Pedro Guimarães Filho, BristotMenegon Vilson, Lucas Da Rold Marques, Norton Ferreira Feil, Tiago Comin Colombo

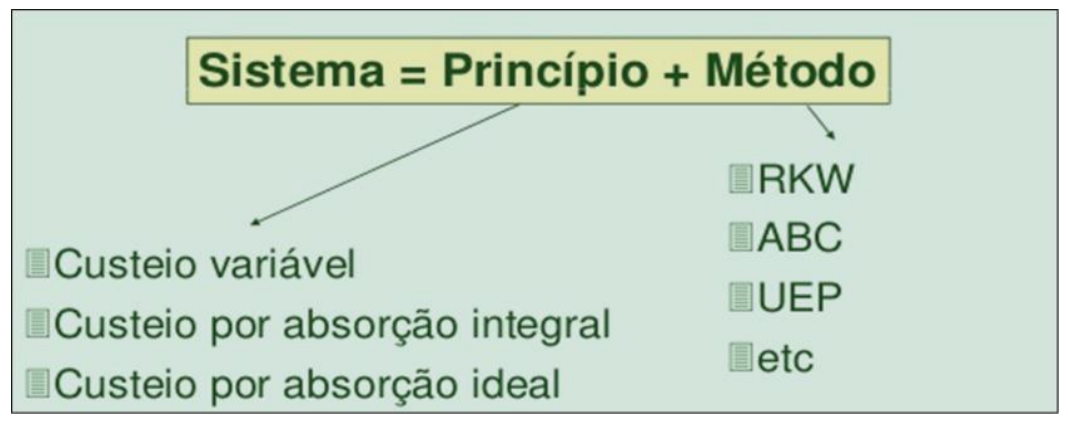

Figura 1 - Sistema de Custos

Fonte: Bornia (2010)

Segundo Bornia (2010), o sistema de acumulação de custos corresponde ao ambiente básico no qual operam os sistemas e as modalidades de custeio. Os princípios e métodos de custeio mais utilizados em empresas de manufatura são os apresentados na Figura 1, que serão melhor descritos no decorrer deste trabalho.

\subsection{Princípios de Custeio}

Wernke (2004) define custeio como o ato de atribuir custos aos produtos, independentemente do tipo de custo que está sendo atribuído. Os princípios de custeio, de acordo com Bornia (2010), são filosofias básicas a serem seguidas pelos sistemas de custos, de acordo com o objetivo e/ou o período de tempo no qual se realiza a análise, uma vez que identificam o tratamento dado pelo sistema aos custos fixos e dividem-se em: custeio por absorção ideal, custeio por absorção integral e custeio variável.

Em síntese, o custeio por absorção é o método mais tradicional de custeio, que atribui aos produtos todos os custos de fabricação (diretos e indiretos), sendo este validado fiscalmente. Bornia (2010) ressalta que, no custeio por absorção integral, a totalidade dos custos (fixos e variáveis) é distribuída aos produtos. Porém, no custeio por absorção ideal, os custos relacionados com insumos usados de forma não eficiente não são atribuídos aos produtos. 
Aplicação do método UEP na determinação dos custos de uma empresa de revestimentos cerâmicos

Leopoldo Pedro Guimarães Filho, BristotMenegon Vilson, Lucas Da Rold Marques, Norton Ferreira Feil,

Tiago Comin Colombo

Sobre o custeio variável ou direto, Bomfim e Passarelli (2006) citam que se toma em consideração, para custeamento dos produtos, apenas os gastos (custos e despesas) variáveis.

\subsection{Custos Industriais}

Bornia (2010) afirma que, atualmente, o mercado se apresenta competitivo, com produtos de baixo preço, boa qualidade, com frequentes modificações de projeto, curta vida útil e muitos modelos diferentes. A análise de custos hoje é indispensável para as empresas que têm o objetivo de obter o máximo de lucros nos seus produtos e/ou serviços (SOUZA et al., 2012).

Segundo Bornia (2010, p. 15), "Custo de fabricação é o valor dos insumos usados na fabricação dos produtos da empresa". Wernke (2004) cita que os custos são os gastos efetuados no processo de fabricação; são os fatores utilizados na obtenção de um produto, como, por exemplo, matérias primas, salários e encargos sociais da operação, depreciação das máquinas, entre outros.

A contabilidade financeira se preocupa com a incorporação no valor dos estoques de todos os recursos consumidos na produção e que podem ser apresentados, segundo a sua natureza, em três grandes grupos: materiais diretos, mão de obra direta e custos indiretos de fabricação (BRUNI, 2008).

Ainda segundo Bruni (2008), os materiais diretos representam os gastos com matéria prima e embalagens. Já os gastos com mão de obra direta representam o esforço produtivo dos funcionários da produção. Vale ressaltar que ambos são mensurados de forma objetiva, ao contrário dos custos indiretos de fabricação, que são gastos sem mensuração objetiva e que representam todos os demais gastos produtivos que não estão relacionados diretamente com a fabricação de um produto.

\subsection{Classificação dos Custos}

Os custos apresentam várias classificações: dentre estas se destaca a classificação pela variabilidade, onde os custos são classificados considerando sua 
Aplicação do método UEP na determinação dos custos de uma empresa de revestimentos cerâmicos

Leopoldo Pedro Guimarães Filho, BristotMenegon Vilson, Lucas Da Rold Marques, Norton Ferreira Feil,

Tiago Comin Colombo

relação com o volume de produção, sendo dividido em custos fixos e variáveis. Outra classificação bastante importante é quanto à facilidade de alocação, a qual os define como custos diretos e indiretos (BORNIA, 2010).

\subsubsection{Custos Variáveis}

Bertó e Beulke (2013, p. 26) afirmam que os custos variáveis "constituem valores que se modificam em relação direta com o volume vendido". Ainda sobre estes custos, Bornia (2010) define que eles estão intimamente relacionados com a produção; crescem com o aumento do nível de atividade da empresa, como os custos com matéria prima.

\subsubsection{Custos Fixos}

Os custos fixos, segundo Famá e Bruni (2004, p. 32), "são custos que não variam, qualquer que seja o volume de atividade da empresa. Existem mesmo que não haja produção". Bertó e Beulke (2013) afirmam que sua característica é de se manter inalterados face ao volume de atividade, não se modificando em razão do crescimento ou retração do volume de negócios. Bornia (2010, p. 19) afirma que "custos fixos são aqueles que independem do nível de atividade da empresa no curto prazo, não variam com alterações no volume de produção, como o salário do gerente, por exemplo".

\subsubsection{Custos Diretos}

Os custos diretos, segundo Wernke (2004, p. 13), "são os gastos facilmente apropriáveis às unidades produtivas, ou seja, são aqueles que podem ser identificados como pertencentes a este ou àquele produto". Desse modo, os custos diretos são considerados como aqueles que realmente foram consumidos para a execução de determinado produto ou serviço. Bruni (2008) ressalta que os custos diretos podem ser medidos de maneira objetiva, já que é possível identificar a quantidade exata utilizada para a fabricação de um produto. Bornia (2010) cita a matéria prima e a mão de obra direta como os principais exemplos de custos diretos em relação a um produto. 
Aplicação do método UEP na determinação dos custos de uma empresa de revestimentos cerâmicos Leopoldo Pedro Guimarães Filho, BristotMenegon Vilson, Lucas Da Rold Marques, Norton Ferreira Feil, Tiago Comin Colombo

\subsubsection{Custos Indiretos}

Bruni (2008) afirma que os custos indiretos de fabricação representam os gastos identificados com a função de produção ou elaboração do serviço a ser comercializado e que não podem ser associados diretamente a um produto ou serviço. Para Wernke 2004, custos indiretos são aqueles que ocorrem dentro do processo de produção de uma empresa. São os gastos que se têm para exercer suas atividades, mas que não têm relação direta com um produto, pois se relacionam com vários produtos ao mesmo tempo, tendo a necessidade do uso de rateios para serem apropriados aos produtos.

Os custos indiretos, para Bertó e Beulke (2013, p. 25), "apresentam como característica, em geral, a impossibilidade de ser medidos, identificados, quantificados diretamente em cada unidade comercializada". Bornia (2010, p. 21) afirma que "as alocações causam a maior parte das dificuldades e deficiências dos sistemas de custos, pois não são simples e podem ser feitas por vários critérios".

Comumente, os critérios de rateio podem envolver horas-máquina, mão de obra direta, materiais diretos, custo primário ou alguma outra referência básica (BRUNI, 2008).

\subsection{Métodos de Custeio}

Segundo Wernke (2004), a atribuição dos custos variáveis é efetuada facilmente pelas fichas técnicas de um produto, mas quando se lida com custos fixos, é necessário recorrer a métodos específicos de custeamento. Os métodos de custeamento mais conhecidos ou utilizados são o custeio baseado em atividades ( $A B C)$, método dos centros de custos (RKW) e o método da unidade de esforço da produção (UEP).

\subsubsection{Método do Centro de Custos (RKW)}

Bornia (2010) afirma que o Método RKW, também conhecido como método das seções homogêneas ou mapa de localização, trabalha apenas com os custos indiretos, não sendo apropriado para os custos com matérias primas. 
Aplicação do método UEP na determinação dos custos de uma empresa de revestimentos cerâmicos Leopoldo Pedro Guimarães Filho, BristotMenegon Vilson, Lucas Da Rold Marques, Norton Ferreira Feil, Tiago Comin Colombo

Segundo Bertó e Beulke (2013), a característica principal deste método é a setorização dos custos nos denominados "centros de custos" ou "centros de responsabilidade". A partir disso, os custos são rateados para os centros da atividade afim. A etapa final consiste em repassar os custos para os produtos ou serviços, em razão do volume de sua produção.

Os centros de custos podem ser determinados considerando o organograma, a localização, as responsabilidades e a homogeneidade. Quanto à classificação dos centros de custos, estes são separados em: (a) diretos, os que trabalham diretamente com o produto; (b) indiretos, os que prestam apoio aos centros diretos (BORNIA, 2010).

Para Bornia (2010), os procedimentos do método dos centros de custos passam por cinco fases: separação dos custos em itens; divisão da empresa em centros de custos; identificação dos custos com os centros (distribuição primária); distribuição dos custos dos centros indiretos até os diretos (distribuição secundária); e, por fim, a distribuição dos custos dos centros diretos aos produtos (distribuição final).

Passarelli e Bomfim (2006) afirmam que o benefício maior dessa classificação é permitir que os custos sejam acumulados em uma conta operacional relacionada a uma responsabilidade específica, o que permitirá seu controle em relação aos objetivos traçados para o titular dessa responsabilidade.

Atualmente, os custos indiretos assumiram proporções mais significativas na estrutura de custos dos produtos; assim, os rateios utilizados para apropriação desses custos, neste método de custeio, podem proporcionar divergências ou imprecisões que influenciam diretamente na formação de preço e na tomada de decisão.

\subsubsection{Método de Esforço de Produção (UEP)}

Segundo Allora e Oliveira (2010), foi durante a segunda Grande Guerra Mundial que se teve as primeiras ideias deste método. O engenheiro francês, Georges Perrin, desenvolveu um estudo para determinar uma única unidade de medida para medir uma produção diversificada, sendo denominada como GP. Anos mais tarde, o também engenheiro italiano Franz Allora veio ao Brasil por motivos profissionais, onde acabou 
Aplicação do método UEP na determinação dos custos de uma empresa de revestimentos cerâmicos Leopoldo Pedro Guimarães Filho, BristotMenegon Vilson, Lucas Da Rold Marques, Norton Ferreira Feil,

Tiago Comin Colombo

se estabelecendo. Após sua aposentadoria, montou uma empresa de consultoria em Blumenau-SC, onde, durante todos os anos de suas atividades, desenvolveu esta técnica de medição de produção, o que ocasionou a criação de um novo conceito: UEP (Unidade de Esforço de Produção).

O método da UEP está pautado na unificação da produção, visando simplificar o processo de controle de gestão, e, com isso, as análises de desempenho de uma empresa são realizadas a partir de custos e medidas físicas de eficiência, eficácia e produtividade (BORNIA, 2002).

$\mathrm{A}$ abordagem de tratamento dos custos relacionados à produção realizada pelo método UEP difere dos demais métodos de custeio tradicionais. Segundo Bornia (2010), este método trabalha somente com custos de transformação, sendo que os custos com matérias primas não são analisados pelo método, devendo ser tratados separadamente. Bornia (2010, p. 141) afirma: "A unificação da produção, no método da UEP, parte do conceito teórico de esforço de produção". "Os esforços de produção significam todo o esforço utilizado para transformar a matéria-prima nos produtos acabados da empresa" (WERNKE, 2004, p. 33).

Allora e Oliveira (2010) afirmam que se pode tentar entender o esforço de produção segundo a Figura 2, sendo este definido como o trabalho realizado pela fábrica para transformar a matéria prima (MP) em produto acabado (PA). Este esforço será composto por humanos, capital, energia, entre outros.

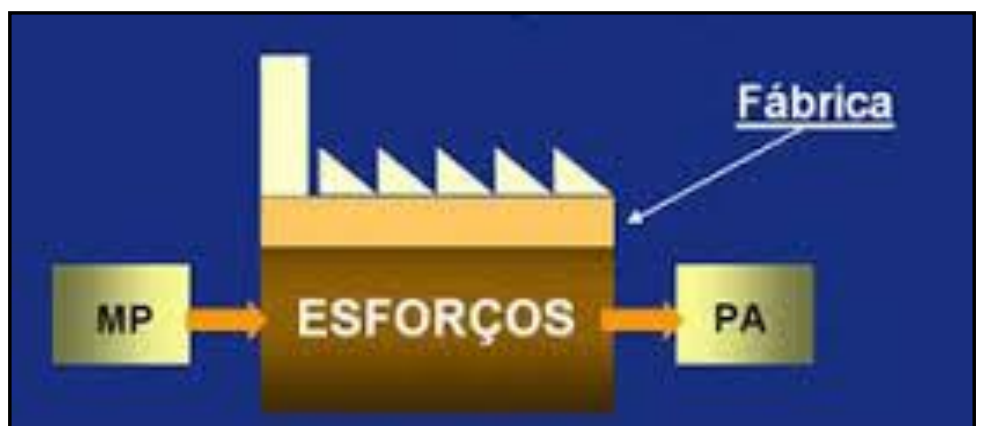

Figura 2 - Gráfico de representação do esforço de produção Fonte: Allora e Oliveira (2010). 
Aplicação do método UEP na determinação dos custos de uma empresa de revestimentos cerâmicos

Leopoldo Pedro Guimarães Filho, BristotMenegon Vilson, Lucas Da Rold Marques, Norton Ferreira Feil, Tiago Comin Colombo

Bornia (2010) afirma que os focos concentradores dos esforços de produção são todas as atividades produtivas diretamente envolvidas na fabricação dos produtos, sendo estes denominados postos operativos.

Wernke (2004) afirma que, para utilizar o método UEP, devem-se seguir oito etapas para a implantação do método. O Quadro 1 apresenta as etapas de implantação do Método da UEP.

\begin{tabular}{|c|c|}
\hline Etapas & Descrição \\
\hline $\begin{array}{l}\text { Divisão da fábrica em } \\
\text { postos operativos }\end{array}$ & $\begin{array}{l}\text { Posto operativo é um conjunto formado por operações produtivas } \\
\text { elementares, semelhantes para todos os produtos que passam pelos } \\
\text { postos operativos, diferenciando somente pelo tempo de passagem. } \\
\text { Podem-se agregar diferentes máquinas em um mesmo posto operativo, } \\
\text { mas quando se tratar de máquinas e equipamentos com diferentes } \\
\text { capacidades produtivas, então se deve agrupá-los separadamente. }\end{array}$ \\
\hline $\begin{array}{l}\text { Determinação dos } \\
\text { índices de custos } \\
\text { horários por posto } \\
\text { operativo FIPO (ou o } \\
\text { custo/hora por posto } \\
\quad \text { operativo) }\end{array}$ & $\begin{array}{c}\text { Procura-se identificar os índices de custos horários por posto operativo. } \\
\text { Esses índices de custos são calculados tecnicamente, de acordo com o } \\
\text { efetivo dispêndio de insumos por parte dos postos operativos. Este } \\
\text { procedimento é realizado pelo levantamento dos insumos consumidos em } \\
\text { cada posto operativo em certo período, realizando a divisão do valor } \\
\text { obtido (em } \mathrm{R} \$ \text { ) dos custos de transformação destes pela quantidade de } \\
\text { horas trabalhadas. }\end{array}$ \\
\hline $\begin{array}{l}\text { Escolha do produto- } \\
\text { base }\end{array}$ & $\begin{array}{l}\text { A escolha do produto-base deverá recair sobre o produto que melhor } \\
\text { representar a estrutura de produção da fábrica. Pode ser um produto que } \\
\text { passe pelo maior número de postos operativos ou que percorra os postos } \\
\text { mais importantes. Para que esta definição seja possível, o produto base } \\
\text { poderá ser uma combinação fictícia de vários produtos. }\end{array}$ \\
\hline $\begin{array}{l}\text { Obtenção dos tempos } \\
\text { de passagem dos } \\
\text { produtos pelos postos } \\
\text { operativos }\end{array}$ & $\begin{array}{l}\text { De posse dos tempos de passagem do produto base pelos postos } \\
\text { operativos e dos foto-índices, calcula-se o custo do produto base nesse } \\
\text { instante, denominado foto-custo base. }\end{array}$ \\
\hline $\begin{array}{l}\text { Cálculo dos potenciais } \\
\text { produtivos (UEP/hora) } \\
\text { de cada posto operativo }\end{array}$ & $\begin{array}{l}\text { Com a apuração do foto-custo base, parte-se para o cálculo dos } \\
\text { potenciais produtivos, que seria a quantidade de esforços de produção } \\
\text { gerada pelo funcionamento de um posto operativo por hora. }\end{array}$ \\
\hline $\begin{array}{l}\text { Definição dos } \\
\text { equivalentes dos } \\
\text { produtos em UEP (valor } \\
\text { em UEP do produto) }\end{array}$ & $\begin{array}{l}\text { Para a definição dos equivalentes dos produtos em UEP, deve-se } \\
\text { multiplicar o tempo de passagem de um produto no posto operativo pelo } \\
\text { potencial produtivo deste posto. }\end{array}$ \\
\hline $\begin{array}{c}\text { Mensuração da } \\
\text { produção total em UEP }\end{array}$ & $\begin{array}{l}\text { Posteriormente, realizando uma nova multiplicação das quantidades } \\
\text { produzidas de cada produto pelos seus respectivos equivalentes, } \\
\text { encontra-se a produção em UEP. }\end{array}$ \\
\hline $\begin{array}{l}\text { Cálculo dos custos de } \\
\text { transformação }\end{array}$ & $\begin{array}{l}\text { Por meio da razão entre os gastos totais com os postos operativos pela } \\
\text { produção total em UEP e, posteriormente, pela multiplicação do valor } \\
\text { obtido pelos equivalentes de cada produto, apura-se assim o custo de } \\
\text { transformação. }\end{array}$ \\
\hline
\end{tabular}

Quadro 1 - Etapas de implantação do método da UEP

Fonte: Adaptado de Wernke (2004); Bornia (2010); Allora e Oliveira (2010). 
Aplicação do método UEP na determinação dos custos de uma empresa de revestimentos cerâmicos Leopoldo Pedro Guimarães Filho, BristotMenegon Vilson, Lucas Da Rold Marques, Norton Ferreira Feil, Tiago Comin Colombo

Bornia (2010) afirma que a grande vantagem do método UEP está na simplicidade de operacionalização. A alocação dos custos de transformação de bens ou serviços e o acompanhamento dos índices de desempenho, que devem ser feitos periodicamente, se tornam muito fáceis e rápidos, depois de se conhecer os potenciais produtivos de cada posto e os equivalentes em UEPs dos produtos. Segundo Wernke (2004), o uso do método UEP proporciona o acompanhamento do desempenho fabril mediante o acompanhamento da produção por meio de medidas físicas de desempenho. Esses índices podem ser determinados para um posto operativo, um setor da empresa ou para toda a fábrica.

Conforme citam Allora e Oliveira (2010), a metodologia UEP proporciona uma série de vantagens, dentre elas:

- Grande clareza e precisão em saber quem perde e quem ganha, até entre milhares de produtos através de conhecimento do custo de cada produto em relação ao seu desempenho de venda;

- Substancial e rápida melhoria dos lucros reais da empresa em função do estudo aprimorado do seu mix de vendas;

- Aumento do volume de vendas pela venda eventual da capacidade ociosa; assim aumenta-se a produção, reduzindo-se os custos de fabricação;

- Permite sua implantação e utilização paralelamente ao sistema vigente em sua empresa, sem qualquer interferência nos resultados do mesmo.

O entendimento principal é de que, se toda a produção estiver expressa em uma única medida, o custo consumido por cada unidade produzida é o mesmo para todos os produtos elaborados. Dessa forma, não há distinções se o produto está expresso em unidades, quilogramas ou litros, pois, para fins de custeamento, todos são medidos pelo esforço de produção consumido no processo produtivo. Assim, aquele produto que consome maior esforço de produção deverá também absorver maior parcela dos custos indiretos da empresa, ocorridos naquele período (OENNING; ROCHA NETO, 2006). 
Aplicação do método UEP na determinação dos custos de uma empresa de revestimentos cerâmicos

Leopoldo Pedro Guimarães Filho, BristotMenegon Vilson, Lucas Da Rold Marques, Norton Ferreira Feil, Tiago Comin Colombo

Conforme Fernandes e Allora (2009), a sistemática do método também se aplica para a aferição do esforço na prestação de serviços - a UEPS (Unidade de Esforço da Prestação de Serviços), tema de dissertação de mestrado.

\section{METODOLOGIA}

A metodologia utilizada para a realização da pesquisa se caracteriza como um estudo de caso de natureza exploratória e abordagem quantitativa dos dados. Segundo Gil (2008), o estudo de caso é um estudo profundo e exaustivo de um ou mais objetos, de modo que possibilite seu amplo e detalhado conhecimento.

Com relação às pesquisas exploratórias, segundo Gil (2008), estas têm como objetivo proporcionar maior familiaridade com o problema, com vistas a torná-lo mais explícito. Pode-se dizer que estas pesquisas têm como objetivo principal o aprimoramento de ideias ou a descoberta de intuições.

No intuito de fundamentar o estudo proposto, inicialmente realizou-se uma pesquisa bibliográfica. Segundo Fachin (2003), pesquisa bibliográfica se refere ao conjunto de conhecimentos humanos reunidos em obras, que têm como finalidade conduzir o leitor a determinado assunto. Para a coleta e análise dos dados, será utilizada uma abordagem quantitativa, onde Gurgacz e Nascimento (2007) afirmam que significa traduzir em números opiniões e informações para classificá-las e analisá-las.

Segundo Sakamoto e Allora (2001), para que o método seja viabilizado, há a necessidade de integração de diferentes áreas, principalmente as pessoas das áreas de Produção e Controladoria (Contabilidade Gerencial). Para a aplicação do método da unidade de esforço de produção, foram aplicadas as oito etapas de implantação do método, definidas por Wernke (2004) e citadas no referencial deste trabalho.

Este estudo foi desenvolvido em uma empresa de revestimentos cerâmicos localizada no Sul de Santa Catarina. A linha, objeto deste estudo, produz três formatos de revestimentos diferentes, com várias referências de características superficiais e estéticas distintas, sendo eles: $20 \times 20 \mathrm{~cm}, 10 \times 20 \mathrm{~cm}$ e $10 \times 30 \mathrm{~cm}$. Vale destacar que 0 
Aplicação do método UEP na determinação dos custos de uma empresa de revestimentos cerâmicos Leopoldo Pedro Guimarães Filho, BristotMenegon Vilson, Lucas Da Rold Marques, Norton Ferreira Feil, Tiago Comin Colombo

fluxo produtivo para qualquer referência não se altera. A escolha desta linha se justifica por representar atualmente $50 \%$ do volume de produção da unidade e, segundo a gestão, é alvo de grupos de trabalho para redução de custo de produção.

A empresa trabalha 24 horas por dia, em três turnos de produção, e no mês de dezembro de 2015, mês utilizado como base para o estudo, foram trabalhados 28 dias. O processo de fabricação de revestimentos cerâmicos caracteriza-se por apresentar fluxo contínuo, com sequência linear e produtos padronizados. Sobre o processo adotado pela empresa, este se caracteriza como via úmida, que utiliza a água na moagem das matérias primas. A sequência de operação do processo de fabricação de revestimentos cerâmicos tem início com a etapa de preparação de massa, que trata da dosagem de cada matéria prima, segundo uma formulação.Esta composição é encaminhada para moinhos com bolas de alta alumina que, por meio da rotação com a presença de água, proporciona uma composição homogênea, denominada "barbotina". A barbotina passa pelo processo de peneiramento para retirar o resíduo grosseiro; posteriormente, é bombeada até um equipamento denominado atomizador, que retira a água em excesso, gerando um pó granulado, que é armazenado em silos para posterior prensagem.

Vale destacar que a preparação de massa e atomização da empresa é realizada por outra unidade. Assim, o pó atomizado utilizado para prensagem é considerado, em termos de custo, como matéria prima.

$\mathrm{Na}$ etapa da prensagem, o pó atomizado alimenta as cavidades da prensa e é submetido a uma pressão específica, tendo sua forma definida, denominada vulgarmente "biscoito". Posteriormente, tem-se a etapa de secagem, com a finalidade de eliminar a água presente nas peças para posterior decoração, por meio da aplicação de uma camada de esmalte. O esmalte e as tintas utilizadas na etapa de decoração são desenvolvidos em uma unidade auxiliar denominada preparação de esmaltes.

Após o processo de aplicação do esmalte na peça, tem-se a etapa de queima, onde o produto adquire suas características finais, como a resistência mecânica e abrasiva; além disso, é nesta etapa que as cores são fixadas com mais nitidez. 
Aplicação do método UEP na determinação dos custos de uma empresa de revestimentos cerâmicos Leopoldo Pedro Guimarães Filho, BristotMenegon Vilson, Lucas Da Rold Marques, Norton Ferreira Feil, Tiago Comin Colombo

$\mathrm{Na}$ saída de cada forno, o setor de classificação identifica os defeitos superficiais visualmente, enquanto os defeitos dimensionais são verificados por equipamentos eletrônicos. Posteriormente, as peças são embaladas automaticamente, identificadas, paletizadas e, por fim, transportadas para expedição por máquinas empilhadeiras.

A empresa utiliza como método de custeio o método do centro de custos, que serviu como base para a coleta de informações deste trabalho, mais precisamente para o levantamento dos principais itens de custos da empresa, como: mão de obra direta, encargos sociais, material de consumo, manutenção, energia elétrica, combustível (gás), depreciações.

A empresa não autorizou a exposição dos dados. Assim, utilizou-se um fator de divisão para os valores dos itens de custo que foram identificados.

Ao final da discussão dos resultados, realiza-se uma análise a partir da utilização conjugada do método UEP com a ferramenta de qualidade, denominada "Diagrama de Pareto", a fim de se priorizar o exame de elementos críticos, onde ocorrem os maiores esforços de produção no processo de fabricação dos produtos e podem impactar significativamente no custo, possibilitando identificar causas e definir melhorias ao processo industrial.

\section{ANÁLISE DOS RESULTADOS}

A primeira etapa realizada para análise do método da UEP, na determinação dos custos da produção de revestimentos cerâmicos, foi a divisão da fábrica em postos operativos. Estes foram estabelecidos de acordo com o fluxo produtivo, estando cada posto operativo associado a uma etapa de produção e, em alguns casos, optou-se por agrupar máquinas e equipamentos, em virtude de as operações serem semelhantes ou servirem de ligação de uma etapa para outra. Este procedimento não interfere na composição do custo final. Sendo assim, foram determinados seis postos operativos, como se observa na Figura 3.

Uma das justificativas da aplicação deste trabalho em uma única linha produtiva está relacionada à identificação dos postos operativos, pois, como cada linha apresenta 
Aplicação do método UEP na determinação dos custos de uma empresa de revestimentos cerâmicos Leopoldo Pedro Guimarães Filho, BristotMenegon Vilson, Lucas Da Rold Marques, Norton Ferreira Feil, Tiago Comin Colombo

equipamentos com capacidades produtivas diferentes, não seria possível agrupá-los em um mesmo posto operativo. O ideal é aplicar este método para cada linha de produção, que proporciona maior complexidade devido à grande quantidade de informações. Após a primeira etapa de definição dos postos operativos, parte-se para o cálculo do custo/hora por posto operativo, mas, primeiramente, foi realizada a análise das informações relacionadas ao custo da empresa, apurando os principais itens de custo assim como atribuindo os valores de cada item aos postos operativos, seguindo critérios específicos de rateio. Procurou-se utilizar os itens de custos relacionados ao processo de transformação, que são considerados pelo método de custeio utilizado pela empresa.

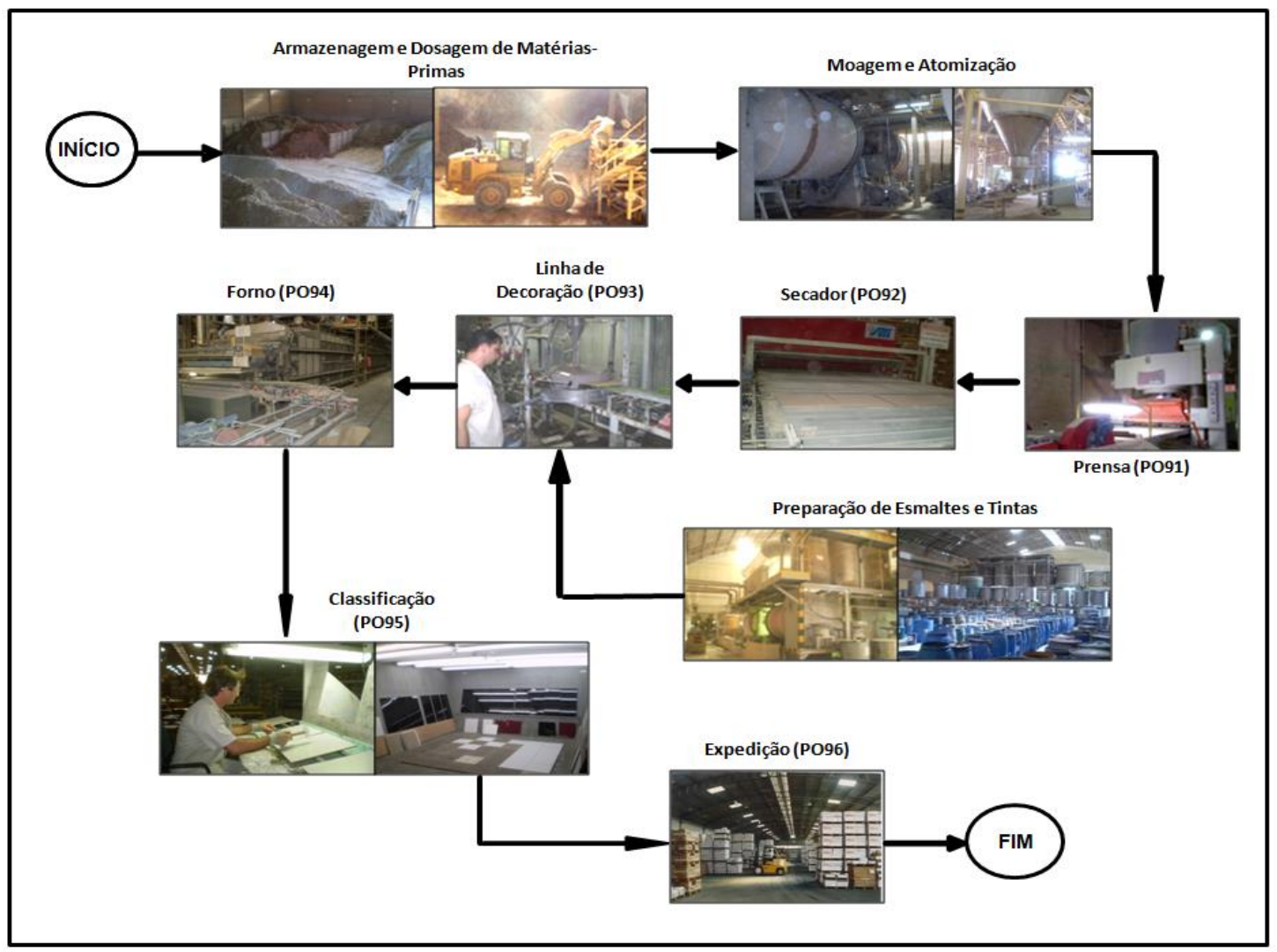

Figura 3 - Divisão da fábrica em postos operativos Fonte: Dados da pesquisa.

Na Figura 4, pode-se observar a composição do custo da empresa. 
Aplicação do método UEP na determinação dos custos de uma empresa de revestimentos cerâmicos Leopoldo Pedro Guimarães Filho, BristotMenegon Vilson, Lucas Da Rold Marques, Norton Ferreira Feil,

Tiago Comin Colombo

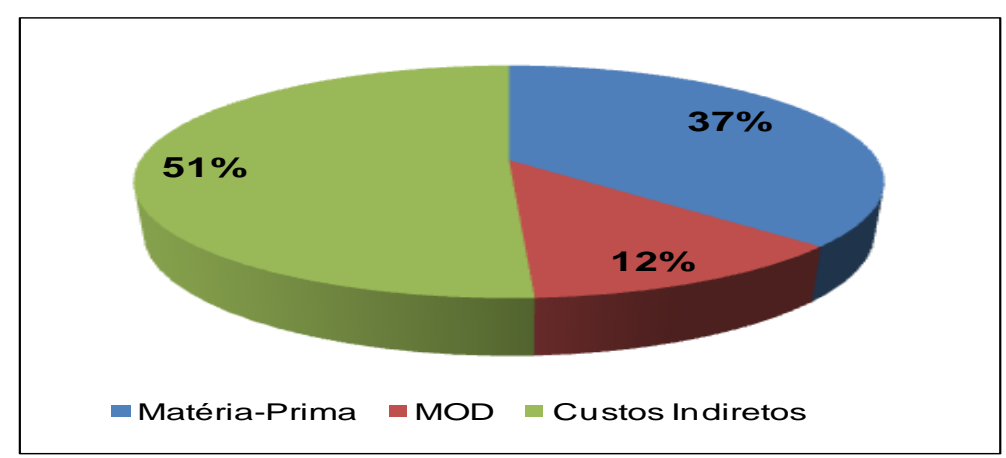

Figura 4 - Gráfico de composição dos custos da empresa estudada Fonte: Dados da pesquisa.

Verifica-se que $51 \%$ dos custos estão relacionados aos custos indiretos; assim necessitam de algum tipo de rateio para serem alocados ao produto, o que ressalta ainda mais a importância de critérios de rateio, para melhorar a acuracidade dos custos aos produtos.

Pode ser observado na Tabela 1 que, dentre os custos identificados no processo de transformação, tem-se a mão de obra direta e os encargos sociais. Os valores demonstrados foram alocados a cada posto operativo, considerando o número de funcionários por posto operativo. Vale destacar que, em alguns casos, um mesmo colaborador desempenha atividades em mais de um posto de trabalho. Nestes casos, foi avaliado o esforço efetivamente gasto por este em cada posto operativo, por meio da análise e acompanhamento da rotina de trabalho e questionamentos com os próprios funcionários e a liderança. 
Aplicação do método UEP na determinação dos custos de uma empresa de revestimentos cerâmicos Leopoldo Pedro Guimarães Filho, BristotMenegon Vilson, Lucas Da Rold Marques, Norton Ferreira Feil, Tiago Comin Colombo

Tabela 1 - Valores dos Custos Diários por Posto Operativo

\begin{tabular}{c|cccccccc}
\hline & \multicolumn{7}{c}{ Postos Operativos } \\
\cline { 2 - 8 } Itens de Custos & Prensa & Secador & $\begin{array}{c}\text { Linha de } \\
\text { Decoração }\end{array}$ & Forno & $\begin{array}{c}\text { Classificação e } \\
\text { Embalagem }\end{array}$ & Expedição & Total (R\$) Percentual (\%) \\
\hline MOD (R\$) & 15,87 & - & 110,84 & 15,87 & 167,92 & 41,17 & 351,67 & 15,93 \\
Encargos Sociais (R\$) & 11,15 & - & 52,67 & 7,61 & 80,91 & 17,64 & 169,98 & 7,70 \\
Mat. Consumo (R\$) & 1,44 & - & 3,02 & 0,29 & 2,77 & 0,69 & 8,21 & 0,37 \\
Gastos Diversos (R\$) & 8,93 & - & 26,64 & 2,88 & 32,42 & 21,89 & 92,76 & 4,20 \\
Combustível - Gás (R\$) & - & 88,20 & - & 554,81 & - & - & 643,01 & 29,13 \\
Depreciação (R\$) & 41,46 & 1,08 & 47,92 & 91,65 & 11,26 & 4,27 & 197,64 & 8,95 \\
Energia Elétrica (R\$) & 34,59 & 12,04 & 11,65 & 41,56 & 3,88 & 2,28 & 106,00 & 4,80 \\
Manutenção (R\$) & 21,88 & 2,29 & 35,79 & 25,09 & 8,47 & 6,55 & 100,06 & 4,53 \\
Serviços Contratados (R\$) & 95,97 & 1,20 & 19,36 & 3,48 & 9,10 & 17,99 & 147,10 & 6,66 \\
Despesas Preparação de & 360,99 & - & 30,08 & - & - & - & 391,07 & 17,72 \\
Esmalte e Massa(R\$) & & & & & & & & \\
\hline Total dia (R\$) & $\mathbf{5 9 2 , 2 9}$ & $\mathbf{1 0 4 , 8 2}$ & $\mathbf{3 3 7 , 9 6}$ & $\mathbf{7 4 3 , 2 4}$ & $\mathbf{3 1 6 , 7 2}$ & $\mathbf{1 1 2 , 4 6}$ & $\mathbf{2 2 0 7 , 5 0}$ & $\mathbf{1 0 0 , 0 0}$ \\
\hline
\end{tabular}

Fonte: Dados da pesquisa.

Outro custo identificado são os materiais de consumo, que, neste caso, englobam equipamento de proteção individual, uniforme pessoal e material de uso e consumo. Este custo foi apropriado a cada posto operativo de forma proporcional ao custo da mão de obra direta, pois se conclui que está diretamente relacionada a este item de custo. Seguindo a mesma linha de apropriação aos postos operativos, outros custos foram identificados, como os custos com plano de saúde, alimentação, vale transporte, que foram agrupados com a denominação "gastos diversos".

Os gastos com combustível referem-se ao consumo de gás nos secadores e fornos, sendo este o item de custo de maior representação $(29,13 \%)$ da totalidade dos custos, alocados a cada posto operativo de acordo com o consumo em $\mathrm{m}^{3}$ de gás em cada equipamento. Com o conhecimento da relação de gás consumido pelo volume produzido $\left(\mathrm{m}^{3} / \mathrm{m}^{2}\right)$ e os respectivos volumes de produção em $\mathrm{m}^{2}$ de cada tamanho de material, foram obtidos os volumes de gás em $\mathrm{m}^{3}$ utilizados em cada posto operativo. Posteriormente, sendo convertido para valores monetários através do custo em $\mathrm{R} \$ / \mathrm{m}^{3}$ do combustível.

O custo da depreciação dos móveis e equipamentos foi disponibilizado pela contabilidade da empresa, sendo que os valores se referem a cada equipamento e, por 
Aplicação do método UEP na determinação dos custos de uma empresa de revestimentos cerâmicos

Leopoldo Pedro Guimarães Filho, BristotMenegon Vilson, Lucas Da Rold Marques, Norton Ferreira Feil, Tiago Comin Colombo

consequência, se obtém os valores por posto operativo. Os gastos com energia elétrica consumidos no período foram distribuídos aos postos operativos, levando-se em consideração a potência instalada nas máquinas e seu respectivo consumo. A empresa realiza o controle de gasto em energia por equipamento, relacionando a potência instalada e o valor da energia contratada por Kwh.

Outro custo identificado é o valor gasto pelo departamento de manutenção, que contempla o reparo ou conserto das máquinas e equipamentos de cada posto operativo. Com o valor mensal apurado, procurou-se utilizar a requisição de manutenção baseada nas horas gastas para atribuir o valor de forma proporcional a cada posto operativo.

Os custos relacionados a serviços contratados se referem, em grande parte, à contratação de mão de obra terceirizada para manutenção e, principalmente, para serviços de "matrizaria" das prensas, que seriam gastos relacionados à troca de tamanho dos produtos. Verifica-se que as linhas de produção têm a mesma necessidade destes serviços e que os valores destes custos foram disponibilizados por setor. Sendo assim, distribuiu-se a totalidade dos custos por setor com esses serviços de forma igualitária por linha de produção.

A empresa ainda considera, para efeitos de custos, os gastos relacionados à preparação de massa atomizada e esmalte, que são realizados por outras unidades fabris auxiliares, onde todos os custos gerados nesses processos, menos os relacionados à matéria prima, são distribuídos às unidades conforme o consumo. $O$ valor total desses custos, atribuído à unidade fabril, foi apropriado à linha de produção, objeto de estudo de forma proporcional ao consumo de massa atomizada e esmalte em quilogramas. Esses valores foram atribuídos respectivamente aos postos operativos prensa e linha de decoração, pois são os postos que consomem diretamente essas matérias prima.

Para o prosseguimento do processo de aplicação do método UEP, faz-se necessário o conhecimento dos tempos de passagem dos produtos pelos postos operativos. Estes foram obtidos com a controladoria da empresa. Os tempos se 
Aplicação do método UEP na determinação dos custos de uma empresa de revestimentos cerâmicos Leopoldo Pedro Guimarães Filho, BristotMenegon Vilson, Lucas Da Rold Marques, Norton Ferreira Feil, Tiago Comin Colombo

diferenciam de acordo com as dimensões de cada produto. Salienta-se que os três produtos analisados possuem dimensões diferentes e, consequentemente, os tempos de produção tornam-se diferentes. A variável tempo influenciará toda a aplicação do método e, por consequência, toda a apuração dos custos de produção.

A cronoanálise consiste em determinar o tempo de processamento que cada produto recebe nos diferentes POs pelos quais passa. Não basta medir o tempo, mas deve-se determinar o ritmo normal de trabalho, levando em consideração o nível de aprendizado do indivíduo e as paradas necessárias para toalete e outras no dia (SAKAMOTO; ALLORA, 2001).

A próxima etapa realizada refere-se à escolha do produto base, conforme segue na Tabela 2.

Tabela 2 - Tempos (horas) de passagem do produto base pelos postos operativos

\begin{tabular}{cccccccc}
\hline Produto & PO91 & PO92 & PO93 & PO94 & PO95 & PO96 & Total \\
\hline $20 \times 20 \mathrm{~cm}$ & 0,00468 & 0,00469 & 0,00474 & 0,00474 & 0,00485 & 0,00487 & 0,02856 \\
$10 \times 20 \mathrm{~cm}$ & 0,00636 & 0,00639 & 0,00646 & 0,00646 & 0,00718 & 0,00718 & 0,04002 \\
$10 \times 30 \mathrm{~cm}$ & 0,00677 & 0,00682 & 0,00694 & 0,00694 & 0,00794 & 0,00794 & 0,04335 \\
Produto Base & 0,00593 & 0,00597 & 0,00605 & 0,00605 & 0,00665 & 0,00666 & 0,03731 \\
\hline
\end{tabular}

Fonte: Dados da pesquisa.

O produto base deve representar o melhor fluxo produtivo. Como os produtos fabricados nesta linha de produção passam por todos os postos operativos, alterando apenas os tempos de passagem de um tamanho de produto para outro, decidiu-se utilizar um produto base fictício, realizando a média dos tempos de passagem dos três produtos. A utilização desta metodologia proporciona o conhecimento de quais produtos são mais ou menos eficientes no mix existente. Procurou-se realizar a apuração do custo-hora (foto-índice), que é obtido pela divisão dos gastos diários totais pelo total de horas trabalhadas em cada posto operativo (Tabela 3 ). 
Aplicação do método UEP na determinação dos custos de uma empresa de revestimentos cerâmicos Leopoldo Pedro Guimarães Filho, BristotMenegon Vilson, Lucas Da Rold Marques, Norton Ferreira Feil, Tiago Comin Colombo

Tabela 3 - Apuração dos custos hora (foto-índice) e do custo do produto base

\begin{tabular}{cccccc}
\hline P.O. & $\begin{array}{c}\text { Gastos Totais } \\
\text { (R\$\$/dia) }\end{array}$ & $\begin{array}{c}\text { Horas Trabalhadas } \\
\text { (3 turnos/dia) }\end{array}$ & $\begin{array}{c}\text { Custo } \\
\text { hora (R\$) })\end{array}$ & $\begin{array}{c}\text { Tempo } \\
\text { Passagem (h) }\end{array}$ & $\begin{array}{c}\text { Custo Produto } \\
\text { Base (R\$) }\end{array}$ \\
\hline PO91 & 592,29 & 24 & 24,68 & 0,00593 & 0,1465 \\
P092 & 104,82 & 24 & 4,37 & 0,00597 & 0,0261 \\
PO93 & 337,96 & 24 & 14,08 & 0,00605 & 0,0852 \\
PO94 & 743,24 & 24 & 30,97 & 0,00605 & 0,1873 \\
PO95 & 316,72 & 24 & 13,20 & 0,00665 & 0,0878 \\
P096 & 112,46 & 24 & 4,69 & 0,00666 & 0,0312 \\
\hline
\end{tabular}

Fonte: Dados da pesquisa.

$\mathrm{Na}$ Tabela 3, analisa-se a forma de apropriação dos custos/hora trabalhada de cada posto operativo, em função do tempo gasto em cada posto. Se evidenciam os tempos de passagem do produto base pelos postos operativos e o estabelecimento do custo-hora base dos produtos. Com a soma de cada posto operativo, verifica-se o custo base total de uma hora trabalhada pela empresa, sendo este $R \$ 0,5640$. Na Tabela 4 tem-se identificação dos potenciais produtivos (UEP/hora).

Tabela 4 - Determinação dos potenciais produtivos dos postos operativos (UEP/hora)

\begin{tabular}{cccc}
\hline P.O. & $\begin{array}{c}\text { Custo Hora } \\
\text { (RS) }\end{array}$ & $\begin{array}{c}\text { Custo Produto } \\
\text { Base (RS) }\end{array}$ & $\begin{array}{c}\text { UEP/Hora } \\
\text { (RS) }\end{array}$ \\
\hline PO91 & 24,68 & 0,5640 & 43,76 \\
PO92 & 4,37 & 0,5640 & 7,74 \\
PO93 & 14,08 & 0,5640 & 24,97 \\
PO94 & 30,97 & 0,5640 & 54,91 \\
PO95 & 13,20 & 0,5640 & 23,40 \\
PO96 & 4,69 & 0,5640 & 8,31 \\
\hline & & Total & $\mathbf{1 6 3 , 0 9}$ \\
\cline { 3 - 4 }
\end{tabular}

Fonte: Dados da pesquisa.

Os potenciais produtivos dos produtos são obtidos por meio da razão do custohora de cada posto operativo pelo custo total do produto base. Pode-se afirmar que a UEP/hora trata da capacidade de produção, o que possibilita identificar quantas 
Aplicação do método UEP na determinação dos custos de uma empresa de revestimentos cerâmicos Leopoldo Pedro Guimarães Filho, BristotMenegon Vilson, Lucas Da Rold Marques, Norton Ferreira Feil, Tiago Comin Colombo

unidades de produção cada posto poderia produzir por hora trabalhada, considerando o tempo ideal de produção, apurado na Tabela 2. A Tabela 5 mostra o cálculo dos equivalentes de cada produto.

Tabela 5 - Equivalente dos produtos em UEP

\begin{tabular}{cccccccc}
\hline Produto & PO91 & PO92 & PO93 & PO94 & PO95 & PO96 & Total \\
\hline $20 \times 20 \mathrm{~cm}$ & 0,00468 & 0,00469 & 0,00474 & 0,00474 & 0,00485 & 0,00487 & 0,02856 \\
$10 \times 20 \mathrm{~cm}$ & 0,00636 & 0,00639 & 0,00646 & 0,00646 & 0,00718 & 0,00718 & 0,04002 \\
$10 \times 30 \mathrm{~cm}$ & 0,00677 & 0,00682 & 0,00694 & 0,00694 & 0,00794 & 0,00794 & 0,04335 \\
Produto Base & 0,00593 & 0,00597 & 0,00605 & 0,00605 & 0,00665 & 0,00666 & 0,03731 \\
UEP/hora & 43,76 & 7,74 & 24,97 & 54,91 & 23,40 & 8,31 & 163,09 \\
\hline \hline $20 \times 20 \mathrm{~cm}$ & 0,2046 & 0,0364 & 0,1183 & 0,2602 & 0,1135 & 0,0404 & 0,7734 \\
$10 \times 20 \mathrm{~cm}$ & 0,2781 & 0,0495 & 0,1613 & 0,3547 & 0,1679 & 0,0596 & 1,0711 \\
$10 \times 30 \mathrm{~cm}$ & 0,2963 & 0,0528 & 0,1734 & 0,3813 & 0,1857 & 0,0659 & 1,1555 \\
Produto Base & 0,2597 & 0,0462 & 0,1510 & 0,3321 & 0,1557 & 0,0553 & 1,0000 \\
\hline
\end{tabular}

Fonte: Dados da pesquisa.

A multiplicação dos potenciais produtivos pelo tempo de passagem em cada posto operativo resulta nos equivalentes dos produtos em UEP. Na Tabela 5, pode ser observado o cálculo dos equivalentes do produto base, onde o resultado total do equivalente será um número inteiro igual a um.

Dessa forma, é possível obter o equivalente dos demais produtos utilizando o tempo de passagem correspondente. Conclui-se que, como o produto $20 \times 20 \mathrm{~cm}$ tem maior produtividade, pois é produzido em menor tempo que o produto base, o equivalente é menor que um, o que ocorre de forma oposta para os produtos das dimensões $10 \times 20 \mathrm{~cm}$ e 10x30 cm. Em outras palavras, o esforço de produção para gerar um $\mathrm{m}^{2}$ do produto $20 \times 20 \mathrm{~cm}$ é menor comparado ao esforço dos demais produtos.

Para melhorar a visualização, foram convertidos os valores obtidos na Tabela 5 para forma gráfica. Observa-se que o posto operativo secador (PO92) é o que consome a menor quantidade de UEP por produto; em contrapartida, o posto operativo forno (PO94) é o que utiliza maior quantidade de UEP por produto. 
Aplicação do método UEP na determinação dos custos de uma empresa de revestimentos cerâmicos Leopoldo Pedro Guimarães Filho, BristotMenegon Vilson, Lucas Da Rold Marques, Norton Ferreira Feil,

Tiago Comin Colombo

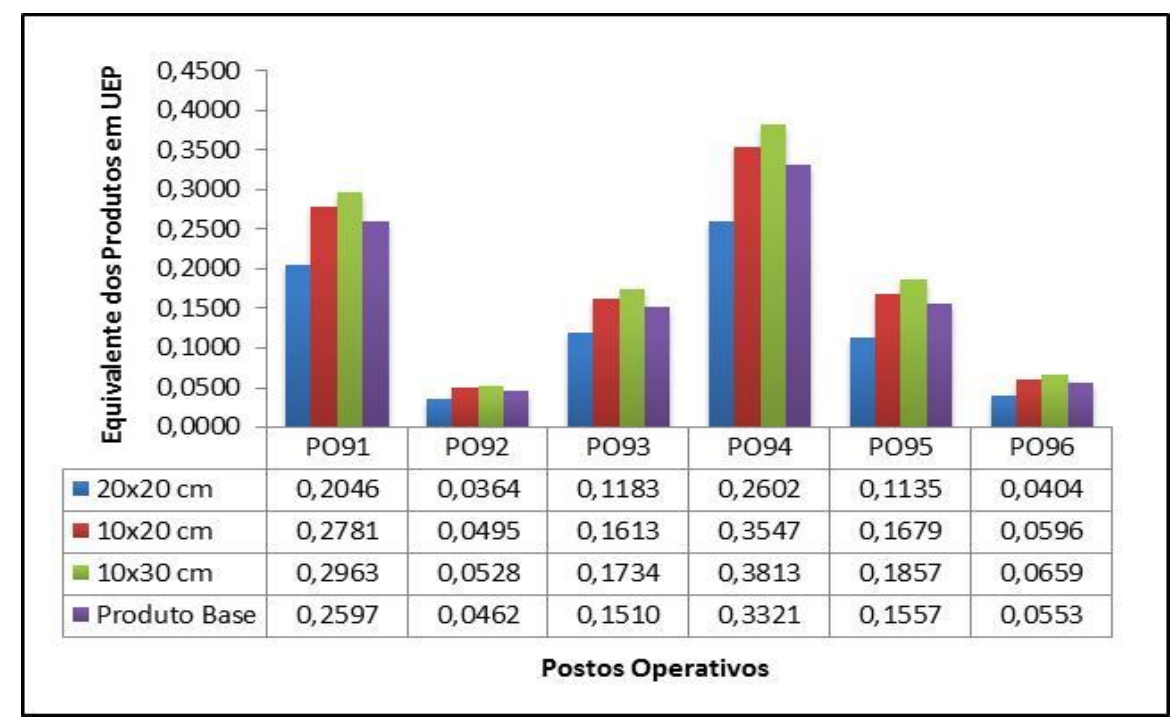

Figura 5 - Quantidade de UEP que cada produto consome por PO Fonte: Dados da pesquisa.

Dando continuidade às etapas, posteriormente se deve realizar a conversão da produção diária em UEP, conforme pode ser observado na Tabela 6. Foram identificados os volumes de produção $\mathrm{em}^{2}$ ao longo do mês definido para aplicação do estudo, obtendo-se as médias de produção diária de cada produto. Para a conversão da produção em UEP, bastou realizar a multiplicação da produção em $\mathrm{m}^{2}$ de cada tamanho de produto com os seus respectivos equivalentes.

Tabela 6 - Produção total em UEP/dia por produto

\begin{tabular}{cccc}
\hline Produto & $\begin{array}{c}\text { Quantidade Diária } \\
\text { Produzida }\left(\mathbf{m}^{2}\right)\end{array}$ & $\begin{array}{c}\text { Equivalente } \\
\text { (UEP) }\end{array}$ & $\begin{array}{c}\text { Total de } \\
\text { UEP's }\end{array}$ \\
\hline $20 \times 20 \mathrm{~cm}$ & 612 & 0,7734 & 473 \\
$10 \times 20 \mathrm{~cm}$ & 2695 & 1,0711 & 2887 \\
$10 \times 30 \mathrm{~cm}$ & 545 & 1,1555 & 630 \\
\hline & & Total & 3990 \\
\cline { 2 - 4 }
\end{tabular}

Fonte: Dados da pesquisa.

A identificação do custo unitário de produção torna-se possível, por meio da divisão dos custos totais de transformação pela produção total em UEPs. Obtém-se, 
Aplicação do método UEP na determinação dos custos de uma empresa de revestimentos cerâmicos Leopoldo Pedro Guimarães Filho, BristotMenegon Vilson, Lucas Da Rold Marques, Norton Ferreira Feil, Tiago Comin Colombo

assim, o custo de transformação de $R \$ 0,5533$, que é considerado como o custo unitário de produção desta linha produtiva ou do mix de produtos para o período analisado. A Tabela 7 apresenta o custo de produção diário apurado de cada produto.

Tabela 7 - Custo de produção (transformação) diário em $\mathrm{m}^{2}$ por produto

\begin{tabular}{cccc}
\hline \multicolumn{2}{c}{$\begin{array}{c}\text { Custo de } \\
\text { Produção (R\$) }\end{array}$} & Total de UEP's & \$/UEP \\
\cline { 2 - 4 } & 2207,50 & 3990 & 0,5533 \\
\hline Produto & Total de UEP's & \$/UEP & Custo Produto (R\$) \\
\hline $20 \times 20 \mathrm{~cm}$ & 473 & 0,5533 & 261,88 \\
$10 \times 20 \mathrm{~cm}$ & 2887 & 0,5533 & 1597,20 \\
$10 \times 30 \mathrm{~cm}$ & 630 & 0,5533 & 348,43 \\
\hline & & Total & $\mathbf{2 2 0 7 , 5 0}$ \\
\cline { 2 - 4 }
\end{tabular}

Fonte: Dados da pesquisa.

O formato $10 \times 20 \mathrm{~cm}$ apresenta o maior custo, já que possui o maior volume de produção e um esforço de produção médio comparado aos demais produtos. Pode ser observado também que o produto $10 \times 30 \mathrm{~cm}$, quando comparado ao $20 \times 20 \mathrm{~cm}$, apresenta o volume de produção diário menor, mas como necessita de maior esforço de produção para ser fabricado, gera um maior custo diário de transformação.

Por fim, foi realizado um comparativo entre os valores do custo de transformação unitário, obtidos de cada produto do método UEP com o do centro de custos (RKW), método utilizado pela empresa. O custo unitário do método UEP foi obtido por meio da divisão do custo diário dos produtos pelas suas respectivas produções diárias. Já o custo unitário pelo método do centro de custos foi disponibilizado pela empresa, sendo somados todos os custos fixos, e os custos com energia elétrica e combustível (gás), considerados como custos variáveis, abrangendo assim todos os custos de transformação definidos pelo método UEP.

Pode ser observado, na Tabela 8, que os custos unitários de transformação entre um método e outro se apresentam próximos; para o produto $20 \times 20 \mathrm{~cm}$, o custo unitário 
Aplicação do método UEP na determinação dos custos de uma empresa de revestimentos cerâmicos Leopoldo Pedro Guimarães Filho, BristotMenegon Vilson, Lucas Da Rold Marques, Norton Ferreira Feil, Tiago Comin Colombo

no método UEP ficou 6,98 \% maior que o custo definido no método do centro de custos. Já para os demais produtos, obteve-se um custo unitário menor.

Tabela 8 - Comparativo do custo de transformação unitário do método UEP x centro de custos

\begin{tabular}{|c|c|c|c|c|c|}
\hline Produto & $\begin{array}{c}\text { Custo Produto } \\
\text { Diário (RȘ) }\end{array}$ & $\begin{array}{l}\text { Quantidade Diária } \\
\text { Produzida }\left(\mathrm{m}^{2}\right)\end{array}$ & $\begin{array}{c}\text { Custo Unitário } \\
\text { UEP (RŞ) }\end{array}$ & $\begin{array}{c}\text { Custo Unitário } \\
\text { RKW (RȘ) }\end{array}$ & Diferença (\%) \\
\hline $20 \times 20 \mathrm{~cm}$ & 261,88 & 612 & 0,43 & 0,40 & 6,98 \\
\hline $10 \times 20 \mathrm{~cm}$ & 1597,20 & 2695 & 0,59 & 0,60 & $(1,69)$ \\
\hline $10 \times 30 \mathrm{~cm}$ & 348,43 & 545 & 0,64 & 0,66 & $(3,13)$ \\
\hline Total & 2207,50 & 3852,00 & 1,66 & 1,66 & - \\
\hline
\end{tabular}

Fonte: Dados da pesquisa.

Para que este comparativo tivesse maior relevância, o ideal seria aplicar o método da UEP em toda a fábrica, o que possibilita observar os ganhos ou perdas do custo unitário que cada produto obterá para cada método utilizado. Sob a ótica de Pareto, constata-se que, dos três produtos analisados, as peças 10x20 cm e $20 \times 20 \mathrm{~cm}$, juntas, são responsáveis por 84,25\% da produção da empresa (Tabela 9, em ordem decrescente). Em função desta característica, o exame se concentrará nesses dois produtos.

Tabela 9 - Participação dos produtos na matriz produtiva

\begin{tabular}{cccc}
\hline PRODUTO & QUANTID. $\left(\mathbf{m}^{2}\right)$ & $\%$ & $\%$ ACUM. \\
\hline $10 \times 20 \mathrm{~cm}$ & 2.815 & $66,67 \%$ & $66,67 \%$ \\
$20 \times 20 \mathrm{~cm}$ & 742 & $17,57 \%$ & $84,25 \%$ \\
$10 \times 30 \mathrm{~cm}$ & 665 & $15,75 \%$ & $100,00 \%$ \\
\hline
\end{tabular}

Fonte: Dados da pesquisa.

A técnica de Pareto será ainda utilizada em mais duas etapas, que são: (1) Identificação das operações de maior esforço dentre os produtos de maior produção; (2) Identificação dos maiores custos nas operações de maior esforço onde podem ser focadas as medidas corretivas. 
Aplicação do método UEP na determinação dos custos de uma empresa de revestimentos cerâmicos Leopoldo Pedro Guimarães Filho, BristotMenegon Vilson, Lucas Da Rold Marques, Norton Ferreira Feil, Tiago Comin Colombo

$\mathrm{Na}$ sequência, verificam-se as operações (postos operativos) que exigem maior esforço de produção para as peças mais produzidas (Etapa 1). Ordenando, de forma decrescente, a coluna "UEP" da Tabela 10, referente ao produto $10 \times 20 \mathrm{~cm}$, obtêm-se os valores abaixo relacionados.

Tabela 10 - Participação do produto $10 \times 20 \mathrm{~cm}$ nos Postos Operativos

\begin{tabular}{cccc}
\hline 10x20 cm & UEP & $\%$ & \% ACUM. \\
\hline FORNO & 0,3547 & 0,3311 & $33,11 \%$ \\
PRENSA & 0,2783 & 0,2597 & $59,08 \%$ \\
CLASSIF. E EMBALAGEM & 0,1680 & 0,1568 & $74,76 \%$ \\
L. DECORAÇÃO & 0,1613 & 0,1505 & $89,81 \%$ \\
EXPEDIÇÃO & 0,0597 & 0,0557 & $95,38 \%$ \\
SECADOR & 0,0495 & 0,0462 & $100,00 \%$ \\
\hline
\end{tabular}

Fonte: Dados da pesquisa.

Observa-se que $89,81 \%$ dos custos de fabricação do produto $10 \times 20 \mathrm{~cm}$ são absorvidos por $66,6 \%$ dos postos operativos (forno, prensa, classificação e embalagens e linhas de decoração). Na Tabela 11, examina-se como o produto $20 \times 20 \mathrm{~cm}$ consome os esforços de produção dos postos operativos com valores de UEP em ordem decrescente.

Tabela 11 - Participação do produto $20 \times 20 \mathrm{~cm}$ nos Postos Operativos

\begin{tabular}{cccc}
\hline 20x20 cm & UEP & $\%$ & $\%$ ACUM. \\
\hline FORNO & 0,2602 & 0,3364 & $33,64 \%$ \\
PRENSA & 0,2048 & 0,2647 & $60,11 \%$ \\
L. DECORAÇÃO & 0,1183 & 0,1530 & $75,41 \%$ \\
CLASSIF. E EMBALAGEM & 0,1135 & 0,1467 & $90,08 \%$ \\
EXPEDIÇÃO & 0,0405 & 0,0523 & $95,31 \%$ \\
SECADOR & 0,0363 & 0,0469 & $100,00 \%$ \\
\hline
\end{tabular}

Fonte: Dados da pesquisa. 
Aplicação do método UEP na determinação dos custos de uma empresa de revestimentos cerâmicos Leopoldo Pedro Guimarães Filho, BristotMenegon Vilson, Lucas Da Rold Marques, Norton Ferreira Feil, Tiago Comin Colombo

A peça $20 \times 20 \mathrm{~cm}$ tem $90,08 \%$ de seus custos lotados nos mesmos postos operativos, correspondendo a 66,6\% do total examinado (4 em 6). Na Etapa 2 e última, pesquisa-se nos postos operativos PRENSA, LINHA DE DECORAÇÃO, FORNO e CLASSIFICAÇÃO E EMBALAGEM, responsáveis por mais de $89 \%$ dos esforços de produção no processo de fabricação dos produtos; foco de medidas corretivas futuras.

Tabela 12 - Participação dos itens de custo no Posto Operativo PRENSA

\begin{tabular}{cccc}
\hline $\begin{array}{c}\text { POSTO OPERATIVO } \\
\text { ITEM DE CUSTO }\end{array}$ & $\mathbf{\$} \mathbf{h}$ & $\%$ & $\%$ ACUMUL \\
\hline Prepar. de esmalte e massa & 15,041 & 0,609 & $60,95 \%$ \\
Serviços contratados & 3,999 & 0,162 & $77,15 \%$ \\
Depreciação & 1,728 & 0,070 & $84,15 \%$ \\
Energia elétrica & 1,441 & 0,058 & $89,99 \%$ \\
Manutenção & 0,912 & 0,037 & $93,69 \%$ \\
MOD & 0,661 & 0,027 & $96,37 \%$ \\
Encargos Sociais & 0,465 & 0,019 & $98,25 \%$ \\
Gastos diversos & 0,372 & 0,015 & $99,76 \%$ \\
Mat. de consumo & 0,060 & 0,002 & $100,00 \%$ \\
Combustível (gás) & 0,000 & 0,000 & $100,00 \%$ \\
\hline
\end{tabular}

Fonte: Dados da pesquisa.

Em PRENSA, quase $90 \%$ dos custos estão concentrados nos itens "preparação de esmalte e massa", "serviços contratados", "depreciação" e "energia elétrica". 
Aplicação do método UEP na determinação dos custos de uma empresa de revestimentos cerâmicos Leopoldo Pedro Guimarães Filho, BristotMenegon Vilson, Lucas Da Rold Marques, Norton Ferreira Feil, Tiago Comin Colombo

Tabela 13 - Participação dos itens de custo no Posto Operativo LINHA DE DECORAÇÃO

\begin{tabular}{cccc}
\hline POSTO OPERATIVO & \multicolumn{3}{c}{ LINHA DE DECORAÇÃO } \\
ITEM DE CUSTO & $\$ \mathbf{h}$ & $\%$ & $\%$ ACUMUL \\
\hline MOD & 4,618 & 0,328 & $32,80 \%$ \\
Encargos Sociais & 2,195 & 0,156 & $48,38 \%$ \\
Depreciação & 1,997 & 0,142 & $62,56 \%$ \\
Manutenção & 1,491 & 0,106 & $73,15 \%$ \\
Prepar. de esmalte e massa & 1,253 & 0,089 & $82,05 \%$ \\
Gastos diversos & 1,110 & 0,079 & $89,93 \%$ \\
Serviços contratados & 0,807 & 0,057 & $95,66 \%$ \\
Energia elétrica & 0,485 & 0,034 & $99,11 \%$ \\
Materiais de consumo & 0,126 & 0,009 & $100,00 \%$ \\
Combustível (gás) & 0,000 & 0,000 & $100,00 \%$ \\
\hline
\end{tabular}

Fonte: Dados da pesquisa.

Já no posto operativo LINHA DE DECORAÇÃO, boa parcela do custo está nos itens "mão de obra direta", "encargos sociais", "depreciação" e "manutenção", responsáveis por $73,15 \%$ dos gastos deste posto. 
Aplicação do método UEP na determinação dos custos de uma empresa de revestimentos cerâmicos Leopoldo Pedro Guimarães Filho, BristotMenegon Vilson, Lucas Da Rold Marques, Norton Ferreira Feil, Tiago Comin Colombo

Tabela 14 - Participação dos itens de custo no Posto Operativo FORNO

\begin{tabular}{|c|c|c|c|}
\hline \multicolumn{2}{|c|}{ POSTO OPERATIVO } & \multicolumn{3}{|c|}{ FORNO } \\
\hline ITEM DE CUSTO & $\$ / \mathbf{h}$ & $\%$ & $\%$ ACUMUL \\
\hline Combustível (gás) & 23,117 & 0,746 & $74,65 \%$ \\
\hline Depreciação & 3,819 & 0,123 & $86,98 \%$ \\
\hline Energia elétrica & 1,732 & 0,056 & $92,57 \%$ \\
\hline Manutenção & 1,045 & 0,034 & $95,95 \%$ \\
\hline MOD & 0,661 & 0,021 & $98,08 \%$ \\
\hline Encargos Sociais & 0,317 & 0,010 & $99,11 \%$ \\
\hline Serviços contratados & 0,145 & 0,005 & $99,57 \%$ \\
\hline Gastos diversos & 0,120 & 0,004 & $99,96 \%$ \\
\hline Materiais de consumo & 0,012 & 0,000 & $100,00 \%$ \\
\hline Preparação de esmalte e massa & 0,000 & 0,000 & $100,00 \%$ \\
\hline & 30,9683 & & \\
\hline
\end{tabular}

Fonte: Dados da pesquisa.

O posto operativo FORNO tem como seu maior item de custo o "combustível", que corresponde a $74,65 \%$ do custo horário de todo o posto. Buscar outros fornecedores de combustível ou tipos pode ser uma saída para tentar reduzir este item.

O último posto operativo estudado, CLASSIFICAÇÃO E EMBALAGEM, a exemplo do posto "Linha de Decoração", concentra, nos itens "mão de obra direta" e "encargos sociais", a maior parte dos gastos, sem esquecer dos "gastos diversos" que devem ser analisados com cuidado, visando avaliar o tipo de gasto (custos sazonais) para a busca de alternativas mais baratas ou a redução dos itens que não agregam valor. 
Aplicação do método UEP na determinação dos custos de uma empresa de revestimentos cerâmicos Leopoldo Pedro Guimarães Filho, BristotMenegon Vilson, Lucas Da Rold Marques, Norton Ferreira Feil, Tiago Comin Colombo

Tabela 15 - Participação dos itens de custo no Posto Operativo CLASSIFICAÇÃO E EMBALAGEM

\begin{tabular}{|c|c|c|c|}
\hline POSTO OPERATIVO & \multicolumn{3}{|c|}{ CLASSIF. E EMBALAGEM } \\
\hline ITEM DE CUSTO & $\mathbf{\$} / \mathbf{h}$ & $\%$ & $\%$ ACUMUL \\
\hline MOD & 6,997 & 0,530 & $53,02 \%$ \\
\hline Encargos Sociais & 3,371 & 0,255 & $78,56 \%$ \\
\hline Gastos diversos & 1,351 & 0,102 & $88,80 \%$ \\
\hline Depreciação & 0,469 & 0,036 & $92,35 \%$ \\
\hline Serviços contratados & 0,379 & 0,029 & $95,23 \%$ \\
\hline Manutenção & 0,353 & 0,027 & $97,90 \%$ \\
\hline Energia elétrica & 0,162 & 0,012 & $99,13 \%$ \\
\hline Materiais de consumo & 0,115 & 0,009 & $100,00 \%$ \\
\hline Combustível (gás) & 0,000 & 0,000 & $100,00 \%$ \\
\hline Prepar. de esmalte e massa & 0,000 & 0,000 & $100,00 \%$ \\
\hline & 13,1971 & & \\
\hline
\end{tabular}

Fonte: Dados da pesquisa.

\section{CONCLUSÃO}

$\mathrm{Na}$ atual situação em que as empresas se apresentam e que o mercado está exigindo, a formação do custo do produto é um dos pontos mais importantes para as organizações. Uma avaliação inadequada dos processos pode proporcionar a apuração equivocada do custo de produção, afetando diretamente os resultados da organização.

Com o término deste trabalho, pode ser verificado que o método da UEP é uma ferramenta que ajuda na tomada de decisões, pois, por meio deste método de custeio, é possível medir a produção de uma empresa, independentemente do tipo de produto e/ou de quantidade. O método de custeio por Unidade de Esforço de Produção - UEP está à frente dos outros métodos, visto que o mesmo, além de servir como um sistema de custeio, pode ser usado como uma ferramenta de controle para as organizações, o qual serve de apoio para planejar, controlar e medir a eficiência da produção, possibilitando a visualização de em qual setor a empresa deverá investir para obter um melhor desempenho nos seus processos de fabricação. Pôde-se comprovar, pelos 
Aplicação do método UEP na determinação dos custos de uma empresa de revestimentos cerâmicos

Leopoldo Pedro Guimarães Filho, BristotMenegon Vilson, Lucas Da Rold Marques, Norton Ferreira Feil, Tiago Comin Colombo

supervisores, que o produto $10 \times 20 \mathrm{~cm}$, em função de suas características e nível de produção, demanda mais esforço de produção, confirmado pelo método empregado.

O método da UEP pode ser aplicado em diferentes sistemas de produção. Neste trabalho, pôde ser verificada a viabilidade de aplicação em uma empresa de revestimentos cerâmicos, atingindo o objetivo proposto. O custo geral de transformação obtido foi de $\mathrm{R} \$ 0,5533$ por unidade de esforço de produção; dentre os produtos, o $10 \times 20 \mathrm{~cm}$ possui o maior custo diário de produção. Vale destacar que este método foi utilizado de forma paralela ao sistema vigente, e a empresa estudada avaliará se dará continuidade ao seu uso. Salienta-se que os resultados obtidos pelo método UEP ficaram próximos aos do método utilizado pela empresa.

Além da identificação do custo de produção, como já citado, o método proporcionou a visualização da linha de produção da empresa como um todo, bem como suas limitações na capacidade produtiva, podendo ser diagnosticado que, no posto operativo 'secador', apresenta-se o menor esforço de produção, enquanto o 'forno' consome a maior quantidade de UEP por produto.

Cabe ressaltar que este método apresenta boa aderência com métodos da qualidade (Técnica de Pareto), que podem ser aplicados conjuntamente, principalmente em análises mais detalhadas e na identificação dos elementos críticos de grande impacto nos custos e no rendimento do sistema produtivo quando se busca a melhoria contínua dos processos de fabricação. Em sistemas industriais que envolvem grande escala de produção, qualquer economia, mesmo em nível de centavos, pode representar ganhos consideráveis a todo o empreendimento.

Como sugestão para estudos futuros, recomenda-se a aplicação do método da UEP nas demais linhas produtivas e também para as demais unidades da empresa, para que se possa assim obter um custo ideal e que possa ser utilizado de forma estratégica pela empresa, além de permitir sua comparação com o método tradicional empregado. Também se sugere uma melhor avaliação nos processos da empresa, para obter maior eficiência na produção mediante o maior aprofundamento na avaliação dos índices relacionados à capacidade produtiva que o método proporciona. 
Aplicação do método UEP na determinação dos custos de uma empresa de revestimentos cerâmicos Leopoldo Pedro Guimarães Filho, BristotMenegon Vilson, Lucas Da Rold Marques, Norton Ferreira Feil, Tiago Comin Colombo

\section{REFERÊNCIAS}

ALLORA, Valério; OLIVEIRA, Simone Espíndola. (2010). Gestão de Custos: Metodologia para a melhoria da performance empresarial. Curitiba: Juruá, 176 p. $-1^{\circ}$ reimpressão (ano 2012).

ANFACER - Associação Nacional dos Fabricantes de Cerâmica para Revestimento. Disponível em: <http://www.anfacer.com.br>. Acesso em: 04/maio/2016.

BERTÓ, D. J.; BEULKE, R. (2013). Gestão de custos. (3. ed.). São Paulo: Saraiva.

BORGET, João. (2000). 1ํWorkshop sobre Revestimentos Cerâmicos: A influência da queima na variação da tonalidade de revestimentos cerâmicos. Revista Cerâmica Industrial, v.1/6, p.4, p.47-49.

BORNIA, A. C. (2002). Análise gerencial de custos: aplicação em empresas modernas. Porto Alegre: Bookman.

BORNIA, A. C. (2010). Análise gerencial de custos: aplicação em empresas modernas. (3. ed.). São Paulo: Atlas.

BRUNI, A. L. (2008). A administração de custos, preços e lucros. (2. ed.). São Paulo: Atlas.

BRUNI, Adriano Leal; FAMÁ, Rubens. (2004). Gestão de custos e formação de preços. (3. ed.). São Paulo: Atlas S. A., 551 p.

FACHIN, Odília. (2003). Fundamentos de Metodologia. (4. ed.). São Paulo: Saraiva.

FERNANDES, Luciano; ALLORA, Valério. (2009, novembro). Método da unidade de esforço da prestação de serviços (UEPS): uma estimativa de custos para o transporte escolar rural. XVI Congresso Brasileiro de Custos. Fortaleza - CE - Brasil.

GIL, A. C. (2008). Como elaborar projetos de pesquisa. (4. ed.). São Paulo: Atlas.

GURGACZ, Glaci; NASCIMENTO, ZinaraMarcet de A. (2007). Metodologia do Trabalho Científico: Com enfoque nas ciências exatas. Joinville: Sociesc.

MENEGALI, Francine. (2009). Desenvolvimento de técnica com efeito reativo. Universidade do Sul de Santa Catarina, UNISUL, p.17.

OENNING, Vilmar; ROCHA NETO, Anselmo. (2006). O uso do custeamento pelas Unidades de Esforço de Produção (UEP) e a otimização de produção. In: 
Aplicação do método UEP na determinação dos custos de uma empresa de revestimentos cerâmicos Leopoldo Pedro Guimarães Filho, BristotMenegon Vilson, Lucas Da Rold Marques, Norton Ferreira Feil, Tiago Comin Colombo

CONGRESSO BRASILEIRO DE CUSTOS. XIII, 2006, Belo Horizonte. Anais... Belo Horizonte: ABC.

PINTO JUNIOR, Cyro Carlos Garcez. (2008). Diagnóstico do arranjo produtivo local de cerâmica de revestimento do sul de Santa Catarina. 125 f. (Monografia). Universidade Federal de Santa Catarina - UFSC, Florianópolis.

PASSARELI, João; BOMFIM, Eunir de Amorim. (2006). Custos - Análise e Controle. (4. ed.). São Paulo: Thomson.

SAKAMOTO, Frederico T. C.; ALLORA, Valério; OLIVEIRA, Simone Espíndola. (2001, outubro). Melhoramento nas Ferramentas de Gestão: A Implantação da UP' - Unidade de Produção - na Seara Alimentos S/A. ENEGEP 2001 - XXI Encontro Nacional de Engenharia de Produção - VII International Conferenceon Industrial Engineeringand Operations Management, Salvador, BA, Brasil.

WERNKE, Rodney. (2004). Gestão de custos: Uma abordagem prática. (2. ed.). São Paulo: Atlas S. A., $175 \mathrm{p}$.

Data de Submissão: 04/07/2016

Data de Aceite: 06/12/2016 